\title{
Update on genetic screening and treatment for infertile men with genetic disorders in the era of assisted reproductive technology
}

\author{
Seung Ryeol Lee', Tae Ho Lee², Seung-Hun Song ${ }^{2}$, Dong Suk Kim² ${ }^{2}$ Kyung Hwa Choi' ${ }^{1}$, Jae Ho Lee ${ }^{3}$, Dae Keun Kim ${ }^{4}$ \\ 'Department of Urology, CHA Bundang Medical Center, CHA University, Seongnam; '²Department of Urology, Fertility Center, CHA Gangnam Medical \\ Center, CHA University, Seoul; ${ }^{3}$ Department of Biomedical Science, College of Life Science, CHA University, Pocheon; ${ }^{4}$ Department of Urology, CHA \\ Fertility Center Seoul Station, CHA University School of Medicine, Seoul, Korea
}

A genetic etiology of male infertility is identified in fewer than $25 \%$ of infertile men, while $30 \%$ of infertile men lack a clear etiology, resulting in a diagnosis of idiopathic male infertility. Advances in reproductive genetics have provided insights into the mechanisms of male infertility, and a characterization of the genetic basis of male infertility may have broad implications for understanding the causes of infertility and determining the prognosis, optimal treatment, and management of couples. In a substantial proportion of patients with azoospermia, known genetic factors contribute to male infertility. Additionally, the number of identified genetic anomalies in other etiologies of male infertility is growing through advances in whole-genome amplification and next-generation sequencing. In this review, we present an up-to-date overview of the indications for appropriate genetic tests, summarize the characteristics of chromosomal and genetic diseases, and discuss the treatment of couples with genetic infertility by microdissection-testicular sperm extraction, personalized hormone therapy, and in vitro fertilization with pre-implantation genetic testing.

Keywords: Azoospermia; Genetics; Infertility; Spermatozoa

\section{Introduction}

More than $30 \%$ of cases of infertility are related to male factors alone, and male factors alone or in combination with female factors contribute to up to $50 \%$ of all cases of infertility among couples $[1,2]$. Male infertility is related to men's overall health, and genetic abnormalities are thought to cause $13 \%-30 \%$ of cases of male infertility, with azoospermia being the most common phenotype associated with genetic abnormalities [3-5]. However, genetic analyses show no clear etiology of infertility in up to $72 \%$ of affected men, leading to a

Received: March 1,2021 · Revised: June 2, 2021 · Accepted: July 8, 2021 Corresponding author: Dae Keun Kim

Department of Urology, CHA Fertility Center Seoul Station, CHA University School of Medicine, 416 Hangang-daero, Jung-gu, Seoul 04367, Korea Tel: +82-2-2002-0309 Fax: +82-2-2002-0427 E-mail: kdg070723@gmail.com

This is an Open Access article distributed under the terms of the Creative Commons Attribution Non-Commercial License (http://creativecommons.org/licenses/by-nc/4.0/) which permits unrestricted non-commercial use, distribution, and reproduction in any medium, provided the original work is properly cited. diagnosis of idiopathic male infertility [6].

Advancements in reproductive genetics have provided insights into the mechanisms of male infertility, and an important task in male reproductive medicine is to classify idiopathic male infertility based on its causes and elucidate the details of the pathogenesis of this condition. Based on recent progress in genome-analysis technologies, many genetic variations have been shown to be associated with male infertility [7]. Next-generation sequencing technologies have made particularly significant contributions to the search for candidate genes. Therefore, elucidation of the pathophysiology of male infertility through genetic approaches may contribute to increased pregnancy rates in the era of artificial reproductive technology.

Recently, the indications for genetic screening have been updated to achieve the best sensitivity and specificity from genetic tests. For the treatment of severe oligozoospermia and nonobstructive azoospermia (NOA) with genetic disease, hormone therapy or microdissection-testicular sperm extraction (m-TESE) is required. Following rapid technological advances in pre-implantation genetic testing 
(PGT), more technologies have been developed to enable couples known to be at risk for genetic diseases to avoid passing these diseases on to the next generation [8]. Indeed, these approaches can be used to differentiate affected embryos during in vitro fertilization (IVF) by biopsying embryos to test for structural chromosomal abnormalities and single-gene mutations before implantation [9].

In this review, we present updated genetic screening indications for idiopathic infertility in men, discuss the characteristics of structural chromosomal abnormalities and single-gene mutation diseases, and suggest appropriate treatments for infertility-related diseases caused by genetic abnormalities.

\section{Screening for genetic analysis}

\section{Updated indications for karyotype analysis}

In 2021, the American Urological Association (AUA) and American Society for Reproductive Medicine (ASRM) joined to review the diagnosis and treatment of infertility in men and indicated karyotype analysis for azoospermia or severe oligozoospermia (sperm concentration $<5$ million $/ \mathrm{mL}$ ) with elevated follicle-stimulating hormone (FSH) levels, testicular atrophy, or a presumed diagnosis of impaired sperm production as the cause of azoospermia [10]. Additionally, the European Association of Urology (EAU) guidelines state that karyotype analysis should be performed in men with azoospermia or oligozoospermia (sperm concentration $<10$ million $/ \mathrm{mL}$ ) and a family history of recurrent spontaneous abortions, malformations, or mental retardation [11]. However, other studies have evaluated these cutoffs and questioned whether there might be more effective thresholds to screen for karyotype abnormalities. For example, Dul et al. [12] investigated the incidence of chromosomal abnormalities and showed that azoospermia occurred in $15.4 \%$ of infertile men, whereas $0-1,1-5,5-20$, and more than 20 million sperm $/ \mathrm{mL}$ were detected in $3.0 \%, 2.1 \%, 2.7 \%$, and $2.9 \%$ of cases, respectively. These findings suggest that sperm concentration may not be the most effective threshold for recommending karyotype analysis. Current guidelines for oligozoospermia tend to result in over-testing of patients. Additionally, the newly proposed 2021 AUA/ASRM guidelines include recurrent pregnancy loss ( $\geq 2$ ), and European Society of Human Reproduction and Embryology special interest group study for recurrent implantation failure ( $\geq 3$ ) during IVF may also be added to these guidelines [10,13].

\section{Updated indications for Y-chromosome microdeletion}

The AUA, ASRM, and EAU guidelines recommend $Y$ chromosome microdeletion tests for azoospermia or severe oligozoospermia $(<5$ million sperm $/ \mathrm{mL}$ ) with elevated FSH or testicular atrophy $[10,11]$.

A recent systematic review and meta-analysis of European and North American studies estimated the prevalence of Y-chromosome microdeletions according to this guideline and noted that the rate of Y-chromosome microdeletions in azoospermia is approximately $8 \%-12 \%$, whereas those in very severe oligozoospermia (0-1 million sperm $/ \mathrm{mL}$ ), severe oligozoospermia (1-5 million sperm $/ \mathrm{mL}$ ), and sperm concentrations of 5-20 million sperm/mL are approximately $5 \%, 0.8 \%$, and $0.5 \%$, respectively [14]. These results demonstrate that Y-chromosome microdeletions are much less common than previously estimated in men with more than 1-5 million sperm $/ \mathrm{mL}$. In fact, the prevalence of Y-chromosome microdeletions in this population $(0.8 \%)$ is similar to that for which testing is not recommended (more than 5 million sperm/mL; $0.7 \%$ ). Newly published data have shown that Y-chromosome microdeletions are rare (i.e., less than $1 \%)$; thus, future guidelines may recommend and confirm Y-chromosome microdeletion testing for men when sperm concentrations are less than 1 million sperm/mL (Table 1).

\section{Sex chromosome abnormalities}

\section{Klinefelter syndrome}

Chromosome abnormalities occur when there is an error in cell division following mitosis or meiosis. An abnormal number of chromosomes is referred to as aneuploidy, which occurs when one chromo-

Table 1. Current screening thresholds of karyotype analysis and Y-chromosome microdeletion testing and updated new thresholds

\begin{tabular}{|c|c|c|c|c|}
\hline \multirow{2}{*}{ Genetic threshold } & \multicolumn{3}{|c|}{ Current guideline } & \multirow{2}{*}{ New threshold } \\
\hline & AUA & ASRM & EAU & \\
\hline \multirow{3}{*}{$\begin{array}{l}\text { Karyotype abnormality } \\
\text { thresholds }\end{array}$} & $<5$ million sperm $/ \mathrm{mL}$ & $<5$ million sperm $/ \mathrm{mL}$ & $<10$ million sperm $/ \mathrm{mL}$ & NOA \\
\hline & & & & Recurrent pregnancy loss ( $\geq 2$ ) \\
\hline & & & & $\begin{array}{l}\text { Recurrent implantation failure ( } \geq 3 \text { failed embryo } \\
\text { transfers with both fresh and frozen embryos) }\end{array}$ \\
\hline $\begin{array}{l}\text { Y chromosome microdeletion } \\
\text { thresholds }\end{array}$ & $<5$ million sperm $/ \mathrm{mL}$ & $<5$ million sperm $/ \mathrm{mL}$ & $<5$ million sperm $/ \mathrm{mL}$ & $<1$ million sperm/mL \\
\hline
\end{tabular}

AUA, American Urological Association; ASRM, American Society for Reproductive Medicine; EAU, European Association of Urology; nonobstructive azoospermia. 
some is missing from a pair (monosomy) or there are more than two chromosomes in a pair (trisomy, tetrasomy, etc.).

Klinefelter syndrome is associated with small, firm testes with hyalinization of the seminiferous tubules and failure of spermatogenesis. Patients with this syndrome present with clinical features such as tall stature, slightly decreased intelligence, signs of androgen deficiency, and gynecomastia. The karyotype of patients with Klinefelter syndrome is two or more $X$ chromosomes, with 47,XXY being the most common. Symptoms are more severe if three or more $X$ chromosomes are present (e.g., 48,XXXY or 49,XXXXY) [15]. Semen analysis of patients with 47,XXY Klinefelter syndrome typically reveals azoospermia, whereas mosaic Klinefelter syndrome $(46, X Y / 47, X X Y)$ is typically accompanied by severe oligozoospermia to azoospermia.

In addition to reproductive issues, patients with Klinefelter syndrome also exhibit general health problems, such as metabolic syndrome, autoimmune diseases, and psychiatric diseases [16]. Notably, age is the most important predictive factor for the success rate of $\mathrm{m}$-TESE in patients with Klinefelter syndrome, and the success rate has been shown to be higher in men younger than 31 years of age [17]. PGT of embryos resulting from intracytoplasmic sperm injection (ICSI) using sperm from m-TESE is the treatment of choice for patients with Klinefelter syndrome.

\section{47, XYY}

$47, X Y Y$ (Jacob syndrome) is a type of sex chromosomal abnormality related to the occurrence of parental non-disjunction at meiosis II, resulting in the production of an extra $Y$ chromosome and acquisition of the 47,XYY karyotype in affected offspring [18]. Most men with the 47,XYY karyotype are phenotypically taller than average and are at an increased risk of learning problems. Men with 47,XYY syndrome can have variable sperm counts, ranging from normozoospermia to azoospermia. An increased incidence of chromosomally abnormal spermatozoa in the semen is the result of a random event during sperm development [19]. Patients with this condition may receive speech therapy or require extra help with schoolwork, and many patients with $47, X Y Y$ are unaware that they have a sex chromosome abnormality.

\section{46,XX male syndrome}

$46, \mathrm{XX}$ male syndrome (de la Chapelle syndrome) is rare disease that occurs in 1 in 20,000 newborns [20]. The phenotype includes azoospermia, but is notably different from that of Klinefelter syndrome, including a small stature and higher incidence rates of cryptorchidism and ambiguous genitalia [21]. Translocation of sex-determining region $Y$ on the $X$ chromosome is responsible for up to $90 \%$ of cases of $46, X X$ male syndrome. The gene is located below the pseudoautosomal region of the short arm of the $Y$ chromosome, and abnormal translocation can occur during meiosis [22].

$46, X X$ male syndrome presents as azoospermia with a pathology of Sertoli cell-only syndrome (SCOS) on testis biopsy and a sperm retrieval rate of $0 \%$. Therefore, patients with $46, \mathrm{XX}$ male syndrome should not undergo m-TESE. A careful endocrine assessment, including an analysis of FSH, luteinizing hormone, and testosterone levels, and monitoring are recommended.

\section{Autosomal abnormalities}

\section{Translocation}

There are two types of translocations: unbalanced and balanced. Robertsonian translocation is the most common form of unbalanced translocation and is found in $\mathbf{0 . 9 \%}-3.4 \%$ of infertile men [23]. Robertsonian translocations occur when two acrocentric chromosomes break near the centromere, resulting in separation of the long and short arms, and have an incidence of 1:1,000 [24]. The long arms fuse to form one large chromosome, and the short arms fuse to form one small chromosome, which is subsequently lost, resulting in 45 chromosomes [25]. The acrocentric chromosomes in Robertsonian translocations include chromosomes 13, 14, 15, 21, and 22. Carriers of a Robertsonian translocation are phenotypically normal because the lost short arms generally contain nonessential genetic information, resulting in a balanced structural chromosome anomaly [26].

However, this chromosome anomaly can cause meiotic disturbances during spermatogenesis and produce sperm with abnormal genetic material. Owing to the increased rate of unbalanced gametes, patients with Robertsonian translocation are at an increased risk of having aneuploid offspring that can potentially result in miscarriage, congenital anomalies, and babies with trisomy syndromes, such as trisomy 21 (Down syndrome) and trisomy 13 (Patau syndrome). Therefore, these patients should undergo genetic counseling and IVF-ICSI with PGT, which may reduce the miscarriage rate by selecting balanced embryos for implantation during IVF-ICSI [27].

\section{Inversion}

Paracentric inversions occur when the centromere is not included in the inverted segment, whereas pericentric inversions occur when the centromere is included. Although chromosomal inversion is less common than translocation, inversion has been reported to be 13 times more common in infertile men than in the general male population [28]. The majority of inversion carriers are phenotypically normal; however, some people may have a disease secondary to a breakpoint disrupting a gene [29]. The risk of unbalanced gametes in patients with chromosomal inversion depends on the size and location of the inversion, as well as recombination events. Disruptions in meiosis can lead to spermatogenic failure, thereby resulting in infer- 
tility. Therefore, male carriers of chromosome inversions may show various findings in semen analysis, such as azoospermia, oligozoospermia, asthenozoospermia, and normozoospermia.

If unbalanced gametes are produced, genetic counseling should be performed to inform patients of the potential for miscarriage, congenital anomalies, and the transmission of genetic abnormalities, which may affect future male infertility. However, in inversion carriers, the need for PGT is still not clear. Because minimal inversion carriers do not harbor recombinant products, they would not be expected to benefit from PGT. Anton et al. [30] proposed a threshold of greater than $100 \mathrm{Mpb}$ for the size of inverted segments as a possible indication of PGT in patients with chromosomal inversion.

\section{Deletions}

Large chromosome deletions are the least frequent chromosomal abnormalities in infertile men. Carriers of large chromosome deletions are missing a substantial proportion of genetic material. Large autosomal chromosomal deletions may be life-threatening or could result in significant phenotypic abnormalities owing to developmental delays or specific clinical characteristics, including Prader-Willi syndrome, Angelman syndrome, and Williams-Beuren syndrome [31-33]. The clinical characteristics of chromosomal abnormalities are summarized in Table 2.

\section{Y-chromosome microdeletion}

The incidence of $\mathrm{Y}$-chromosome microdeletion is 10\%-15\% in in- fertile men with NOA or severe oligozoospermia [34]. The Y chromosome contains many genes that are important in spermatogenesis and the development of male gonads [35]. The proposed gene region involved in spermatogenesis related to the $Y$ chromosome is named azoospermia factor (AZF); there are three subtypes (AZFa, AZFb, and AZFc). Phenotypes vary depending on the type of AZF region mutation.

\section{AZFa deletions}

Deletion of the entire AZFa region results in SCOS and azoospermia [36]. The AZFa region contains two genes: USP9Y and DBY (DDX3Y) [37]. A diagnosis of complete deletion of the AZFa region indicates that retrieval of testicular sperm is not feasible, as the sperm retrieval rate in patients with deletion of the AZFa region is $0 \%$. Therefore, $\mathrm{m}$-TESE is contraindicated in patients with complete AZFa deletion.

\section{AZFb deletions}

The AZFb region contains two main genes: $R B M Y$ and $P R Y[38,39]$. The genes in the AZFb region support the maturity of spermatozoa and are required for the efficient progression of sperm through meiosis into spermiogenesis [40]. The histological phenotype in patients with complete AZFb or AZFb+c deletions shows SCOS or maturation arrest, leading to azoospermia [41]. The chance to retrieve sperm from $\mathrm{m}$-TESE is negligible in cases of AZFb deletion. Therefore, $\mathrm{m}$-TESE is contraindicated in patients with complete AZFb deletion.

Table 2. Clinical characteristics of chromosomal abnormalities

\begin{tabular}{|c|c|c|c|c|}
\hline Chromosome disorder & Typical karyotype & Semen analysis & Phenotype & Treatment \\
\hline \multirow[t]{2}{*}{ Klinefelter syndrome } & $47, X X Y$ & $\begin{array}{l}\text { Azoospermia-severe } \\
\text { oligospermia }\end{array}$ & $\begin{array}{l}\text { Tall stature, small testis, gyneco- } \\
\text { mastia }\end{array}$ & Micro-TESE+IVF-ICSI+PGT-SR \\
\hline & $46, X X / 47, X X Y$ & & & \\
\hline Jacob syndrome & $47, X Y Y$ & Normal to azoospermia & Tall stature & IVF+PGT-SR \\
\hline $46 \mathrm{XX}$ male syndrome & $46, X X$ & Azoospermia & Small stature, cryptorchidism & AID or adoption \\
\hline Robertsonian translocation & $45, X Y, \operatorname{rob}(14 q 15 q)$ & Normal to severe OAT & Normal & IVF-ICSI+PGT-SR \\
\hline $\begin{array}{l}\text { Balanced reciprocal } \\
\text { translocation }\end{array}$ & Various & Normal to azoospermia & Normal & Various depends on SA \\
\hline Inversion & {$[\operatorname{lnv}(9)]$} & $\begin{array}{l}\text { Clinically insignificant variant } \\
\text { of the normal karyotype }\end{array}$ & Normal & Various depends on SA \\
\hline \multirow[t]{3}{*}{ Deletion } & $\begin{array}{l}\text { Prader-Willi syndrome (deletion } \\
\text { of part of the father's chro- } \\
\text { mosome 15) }\end{array}$ & & Hypotonia, short stature, obesity & $\begin{array}{l}\text { PGT-SR, speech therapy, } \\
\text { growth hormone injection }\end{array}$ \\
\hline & $\begin{array}{l}\text { Angelman syndrome (deletion } \\
\text { of part of the mother's chro- } \\
\text { mosome 15) }\end{array}$ & & $\begin{array}{l}\text { Small head, specific facial fea- } \\
\text { tures, ataxia, happy personality }\end{array}$ & PGT-SR, anticonvulsant \\
\hline & $\begin{array}{r}\text { Williams-Beuren syndrome } \\
\text { (chromosome } 7 \text { deletion) }\end{array}$ & & $\begin{array}{l}\text { cardiac disease, brain function } \\
\text { abnormality }\end{array}$ & $\begin{array}{l}\text { PGT-SR, avoid calcium, vitamin } \\
\text { D, cardiologic evaluation }\end{array}$ \\
\hline
\end{tabular}

TESE, testicular sperm extraction; IVF, in vitro fertilization; ICSI, intracytoplasmic sperm injection; PGT-SR, preimplantation genetic testing-chromosomal structural rearrangement; AID, artificial insemination by donor; OAT, oligoasthenoteratozoospermia; SA, semen analysis. 


\section{AZFc deletions}

The AZFc region contains DAZ, GOLGA2LY, and CSPG4LY [42]. Complete AZFc deletion presents as various types of impaired spermatogenesis [43]. Men with AZFc deletions related to the DAZ gene exhibit variable phenotypes ranging from complete azoospermia to mild oligozoospermia [44]. In a few cases, men with the AZFc deletion have conceived multiple children naturally; however, all of the sons of these men have been found to be infertile [45].

Follow-up studies of patients with AZFc deletions have shown that AZFc microdeletions are associated with a progressive decline in sperm concentration and progression of patients from oligozoospermia to azoospermia [46]. These findings suggest that AZFc deletions could further affect spermatogenesis and worsen the overall sperm quality. Therefore, for men with AZFc deletions who have sperm in the semen, samples should be cryopreserved to prevent possible m-TESE in the future. In 2003, Hopps et al. [47] reported a high sperm retrieval rate $(75 \%)$ in patients with AZFc deletion. m-TESE could be recommended for patients with AZFc deletion, although patients should be informed of the possibility that the deletion may be inherited in their sons.

\section{AZFc partial deletions}

The influence of partial deletions on spermatogenesis is still unclear. None of the currently identified AZFc partial deletions completely eliminate any gene family; however, some have been shown to reduce the copy number of genes. The most clinically relevant AZFc partial deletion is the $\mathrm{gr} / \mathrm{gr}$ deletion, which removes nearly half of the genes present in the AZFc region and therefore affects the dosage of multicopy genes, such as $D A Z, C D Y 1$, and $B P Y 2$, in this region [48]. Men with this deletion are at a significantly increased risk for oligozoospermia [49].

Importantly, the effects of AZFc partial deletions on patients' fertility largely reflect ethnic diversity in spermatogenesis. The reason for these differences is unclear, but they may be related to $Y$ haplogroups and deletion subtypes. This may be clinically relevant because this type of deletion could contribute to the etiology of impaired spermatogenesis. Furthermore, couples should be informed that AZFc partial deletion will be transmitted to their sons and could become complete AZFc deletion in the next generation of male offspring [50].

\section{Single-gene mutations related with abnormal sperm count in spermatogenesis}

\section{Testis-expressed gene 11 (TEX11)}

TEX11 is an X-linked meiosis-specific gene that has been found to be essential for spermatogenesis in humans with a phenotype of NOA [51]. The prevalence of TEX11 mutation in men presenting with
NOA is $2.4 \%$ but can be as high as $15 \%$ when specifically considering men with NOA showing no meiotic arrest with SCOS [52]. The identification of TEX11 can be useful in the diagnostic process and genetic counseling of patients with NOA.

\section{Testis expressed gene 15 (TEX15)}

TEX15 encodes a testis-specific protein that repairs DNA double-stranded breaks [53]. An analysis of testicular histopathology revealed maturation arrest at the primary spermatocyte stage. The TEX15 gene is currently believed to be responsible for spermatogenesis failure.

\section{DEAD-box helicase 3 Y-linked (DDX3Y)}

DDX3Y encodes a conserved RNA DDX3 helicase specifically expressed in pre-meiotic spermatogonial cells [54]. This gene is mapped within the AZFa region, and deletion of this region causes SCOS. DDX3Y expression is required for human fetal germ-cell proliferation, and DDX3Y deletions have been identified in patients with SCOS or severe hypospermatogenesis [55].

\section{Nuclear receptor subfamily 5 group A member 1 (NR5A1)}

Among a cohort of infertile patients, NR5A1 mutations were identified in $3.9 \%$ of those with azoospermia or cryptozoospermia and in $4.3 \%$ of those with severe oligozoospermia [56]. Based on histological analyses, NR5A1 mutations result in SCOS, severe hypospermatogenesis, or partial spermatocyte arrest in patients with NOA.

\section{Heat shock factor 2 (HSF2)}

HSF2 encodes a protein belonging to the HSF family, which activates target genes under stress conditions. In humans, three synonymous mutations and mutations in HSF2 have been identified in cases of azoospermia with maturation arrest at the spermatocyte stage [57].

\section{Doublesex and Mab-3 related transcription factor 1 (DMRT1)}

DMRT1 encodes a testis-specific transcription factor that plays a role in testis differentiation. Deletion of chromosome 9p, which includes DMRT1, is known to be associated with 9p deletion syndrome and $X Y$ gonadal dysgenesis [58]. Smaller deletions and mutations of this gene have been identified in patients with NOA without XY gonadal dysgenesis [59].

\section{Single-gene mutations related to abnormal sperm motility in spermiogenesis}

\author{
1. Multiple morphological abnormalities of the sperm flagella \\ and primary ciliary dyskinesia \\ Multiple morphological abnormalities of the sperm flagella
}


(MMAF) are defined as asthenozoospermia and teratozoospermia resulting from abnormalities concerning the sperm flagella, including absent, irregular, coiled, bent, or angulated sperm flagella. Mutations in the DNAH1 gene are responsible for $25 \%$ of MMAF cases [60]. $D N A H 1$ encodes an axonemal inner dynein arm heavy chain, which often lacks the central pair ( $9+0$ structure).

Primary ciliary dyskinesia (PCD) is a rare autosomal genetic disorder that is multisystemic and is characterized by chronic respiratory tract infections, an abnormal position of internal organs, and motility defects resulting from immotile cilia and flagella [61]. Abnormalities in the DNAI1 and DNAH5 genes account for up to $30 \%$ of all instances of PCD [62].

Ultrastructural defects, such as a lack of dynein arms, as detectable by electronic microscopy, and an absence of radial spokes are a specific feature of PCD [62]. Flagella abnormalities are associated with an elevated frequency of aneuploidy and poor IVF-ICSI outcomes [63]. The lack of $D N A H 1$ leads to a disorganized axoneme with a 9+0 structure and the absence of the central pair [64]. This structural alteration may be linked to a decreased implantation rate.

\section{Single-gene mutations related to abnormal sperm morphology in spermiogenesis}

\section{Globozoospermia}

Globozoospermia is rare, affecting $0.1 \%$ of infertile men, and is characterized by round-headed sperm with few acrosomes, which are unable to fertilize oocytes owing to the lack of an acrosome reaction. Mutations in four genes (DPY19L2, ZPBP, PICK1, and SPATA16) have been shown to be associated with globozoospermia [65].

The most commonly observed genetic defects in patients with globozoospermia are in the DPY19L2 gene. The gene product of DPY19L2 is involved in elongation and acrosome formation [66]. The only fertility option in patients with $100 \%$ globozoospermia is IVF-IC$\mathrm{SI}$. Because a lack of acrosome phospholipase is related to oocyte inactivation, artificial oocyte activation with calcium ionophores or electric activation has been proposed for the treatment of patients with complete globozoospermia. Importantly, men with globozoospermia exhibit high rates of sperm aneuploidy and DNA damage, and couples show low pregnancy rates. Screening for the DPY19L2 gene can be considered as a helpful strategy for men with globozoospermia in order to improve the IVF-ICSI and PGT results and family counseling.

\section{Macrozoospermia}

Macrozoospermia is characterized by large-headed and multi-flagellated spermatozoa. Mutations in AURKC have been shown to be the main genetic cause of sperm macrocephaly, resulting in alterations in meiotic division and tetraploid spermatozoa if both meiotic divisions are affected. Genetic screening of the AURKC gene could reasonably be performed for patients whose sperm contains $30 \%$ or more of large-headed spermatozoa. If a mutation is identified, IVF-IC$\mathrm{SI}$ is contraindicated because the macroscopic selection of spermatozoa combined with fluorescence in situ hybridization analysis and flow cytometry does not enable a correlation between sperm morphology and the genetic content of the nucleus. IVF-ICSI is not contraindicated in patients without mutations, and PGT can be recommended for those with intermediate aneuploid spermatozoa. The genes related to spermatogenesis and spermiogenesis are listed in Table 3 and Figure 1.

\section{Treatment of infertile men with chromosomal and genetic abnormalities}

\section{Clomiphene citrate}

Clomiphene citrate has also shown efficacy when administered prior to $\mathrm{m}$-TESE. An improvement in $\mathrm{m}$-TESE was demonstrated by Hussein et al. [67], who reported that patients receiving therapy with clomiphene citrate had a 20\%-25\% greater chance of having sperm identified in $\mathrm{m}$-TESE than those not receiving any adjuvant treatment. Clomiphene citrate is generally well-tolerated, and common side effects include gastrointestinal distress, hair loss, gynecomastia, and weight gain. Visual disturbances, such as blurred vision and diplopia, occur in $1.5 \%$ of patients [68].

\section{Aromatase inhibitors}

Aromatase is a cytochrome P450 enzyme that irreversibly converts androgens to estrogens in various tissues, including the testis, liver, brain, and adipose tissue [69]. Aromatase inhibitors can be used in NOA to address the imbalances in testosterone and estrogen levels that affect spermatogenesis. Aromatase inhibitors can selectively increase endogenous testosterone levels without increasing estrogens [70]. The effects of aromatase inhibitors on spermatogenesis have also been investigated. Patients with NOA may be prescribed $2.5 \mathrm{mg}$ of letrozole daily for 4 months, which can convert hypospermatogenesis to normal spermatogenesis, as demonstrated by testis biopsy [71].

\section{3. $m$-TESE}

$\mathrm{m}$-TESE can be used for treatment for NOA with or without genetic diseases, such as Klinefelter syndrome, 47XYY, and AZFc deletions. The contraindications for $\mathrm{m}$-TESE are 46,XX male syndrome and AZFa or AZFb deletions. In those cases, hormone replacement and $\mathrm{m}$-TESE should be absolutely avoided. 
Table 3. Genes related to the failure of human spermatogenesis and spermiogenesis

\begin{tabular}{llll}
\hline Gene & \multicolumn{1}{c}{ Full name } & \multicolumn{1}{c}{ Phenotype } & HUGO gene nomenclature ID \\
\hline TEX11 & Testis expressed gene 11 & Spermatocyte maturation arrest & HGNC: 11733 \\
TEX15 & Testis expressed gene 15 & Non-obstructive azoospermia & HGNC: 11738 \\
DDX3Y & DEAD-box helicase 3Y-linked & Spermatocyte maturation arrest & HGNC: 2699 \\
NR5A1 & Nuclear receptor subfamily 5 group A member 1 & Spermatocyte maturation arrest & HGNC: 7983 \\
& & Oligozoospermia & HGNC: 5225 \\
HSF2 & Heat shock factor protein 2 & Spermatocyte maturation arrest & HGNC: 2934 \\
DMRT1 & Doublesex and mab-3 related transcription factor 1 & Non-obstructive azoospermia \\
DNA11 & Dynein axonemal intermediate chain 1 & Asthenozoospermia & HGNC: 2940 \\
& & Flagella abnormality & HGNC: 2954 \\
DNAH5 & Dynein axonemal heavy chain 5 & Asthenozoospermia & \\
& & Flagella abnormality & HGNC: 19414 \\
DPY19L2 & Dpy-19 like 2 & Globozoospermia & HGNC: 15662 \\
ZPBP & Zona pellucida-binding protein 1 & Globozoospermia & HGNC: 9394 \\
PICK1 & Protein interacting with c kinase-1 & Globozoospermia & HGNC: 29935 \\
SPATA16 & Spermatogenesis-associated protein 16 & Globozoospermia & HGNC: 11391 \\
AURKC & Aurora kinase C & Macrozoospermia &
\end{tabular}

HUGO, Human Genome Organisation; HGNC, HUGO Gene Nomenclature Committee.

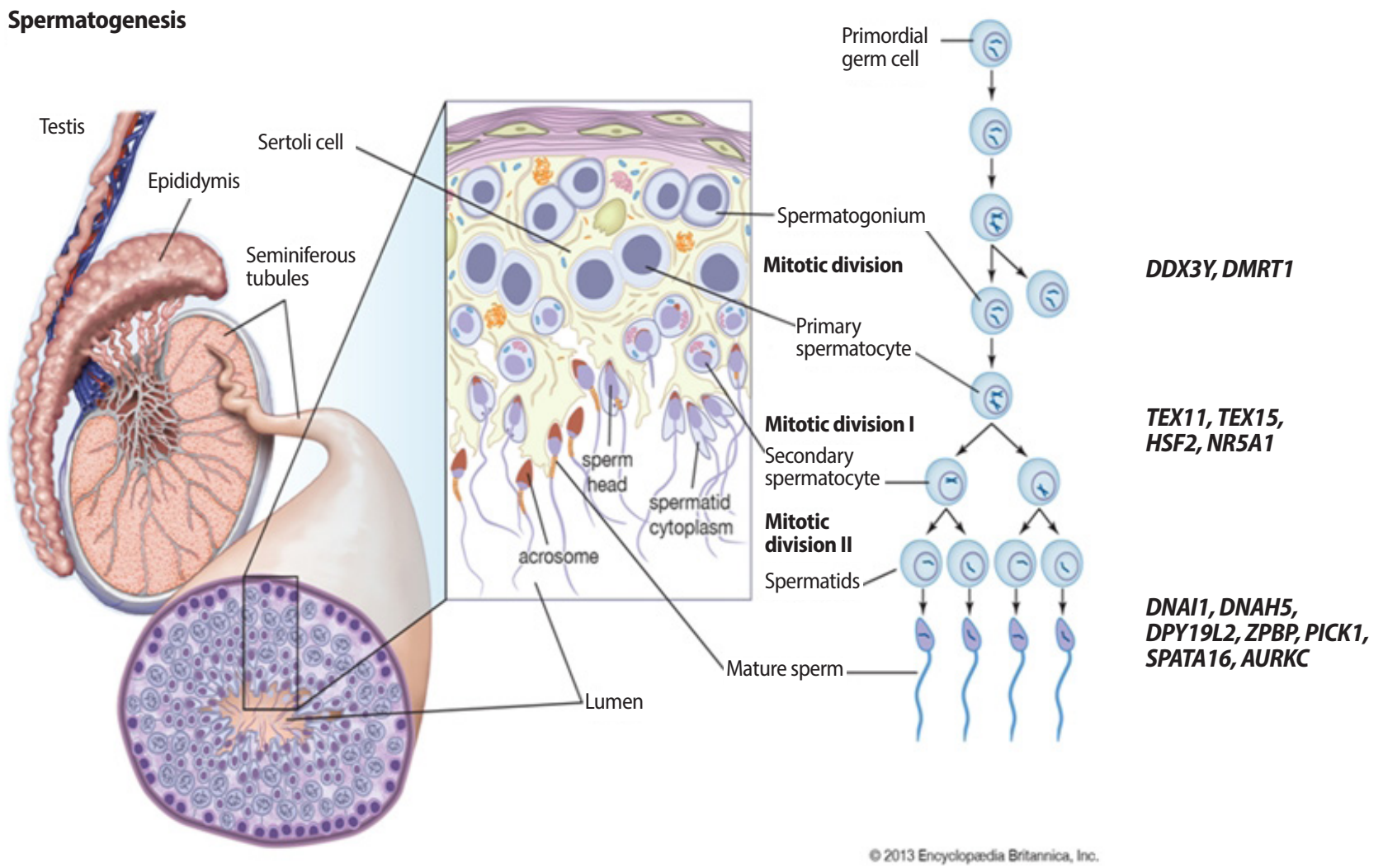

Figure 1. Biological overview of the genetic factors involved in human spermatogenesis and spermiogenesis. DDX3Y, DEAD-box helicase 3 Y-linked; DMRT1, dynein intermediate chain 1, axonemal; TEX11, testis expressed gene 11; TEX15, testis expressed gene 15; HSF2, heat shock factor protein 2; NR5A1, nuclear receptor subfamily 5 group A member 1; DNAI1, dynein intermediate chain 1, axonemal; DNAH5, dynein intermediate chain 5, axonemal; DPY19L2, Dpy-19 like 2; ZPBP, zona pellucida-binding protein 1; PICK1, protein interacting with C kinase-1; SPATA16, spermatogenesis-associated protein 16; AURKC, aurora kinase C. By courtesy of Encyclopædia Britannica, Inc., copyright 2011; used with permission. 


\section{Hormone replacement pretreatment before $m$-TESE}

Positive results have been demonstrated for the use of human chorionic gonadotropin (HCG) hormonal injections in patients with NOA undergoing sperm retrieval in a second round of $m$-TESE. Shiraishi et al. [72] studied therapy with 5,000 IU of HCG three times weekly for 3 months in patients who were previously shown to lack sperm after m-TESE. HCG treatment significantly increased the rate of sperm retrieval at the time of the second round of $m$-TESE compared with men who did not receive HCG treatment. The sperm retrieval rate was $21 \%$ in patients who had undergone HCG treatment. However, no sperm was retrieved in the untreated group [72]. Despite these findings, the results remain inconsistent. For example, in a study of non-mosaic Klinefelter syndrome, Ramasamy et al. [73] found that the sperm retrieval rate during $\mathrm{m}$-TESE did not depend on the preoperative administration of HCG. Additionally, preoperative testosterone levels were found to be a significant predictive factor for the sperm retrieval rate. Patients with testosterone levels greater than or equal to $250 \mathrm{ng} / \mathrm{dL}$ had a $22 \%$ higher sperm retrieval rate than patients with testosterone levels less than $250 \mathrm{ng} / \mathrm{dL}$.

\section{IVF-ICSI with PGT for chromosomal structural rearrangement}

The first report on children born after PGT was published in 1990 by Handyside et al. [74], who described the use of polymerase chain reaction to detect repetitive $Y$-sequences for sex determination in families with X-linked diseases. PGT evolved from an experimental procedure in the early 1990s as an alternative to a well-established clinical procedure. Numerous technical advances in the field of single-cell genetic testing and assisted reproduction have led to extensive changes in PGT practice.

PGT involves the biopsy of a single or few cells from in vitro fertilized oocytes or embryos and testing of the biopsied cells for genetic abnormalities [75]. The selective transfer of embryos unaffected by the study conditions offers the advantages of circumventing an invasive prenatal diagnosis and possible therapeutic termination of pregnancy.

PGT for chromosomal structural rearrangement (PGT-SR) is appropriate for patients with chromosome rearrangements and those who are at risk of creating embryos with an incorrect chromosome number or structure. The indications for PGT-SR include sex chromosome abnormalities and an incorrect chromosome number or structure. (47,XXY Klinefelter syndrome, 47,XYY Jacob syndrome, reciprocal translocation, Robertsonian translocation, or inversion). Many carriers of balanced chromosome rearrangements are healthy and unaware of their carrier status until they try to have children. Carriers of balanced rearrangements are at risk for producing embryos with the incorrect amount of chromosomal material, which typically do not lead to a successful pregnancy. PGT-SR can help identify embryos with the correct amount of chromosomal material that are most likely to lead to a successful pregnancy and healthy live birth.

Reciprocal translocations occur when pieces of genetic material break off from two different chromosomes and swap places. People that carry a balanced translocation can create embryos that have either the same balanced translocation, the unbalanced form of the translocation where there is a gain or loss of chromosomal material, or a completely normal set of chromosomes. If one parent is a carrier of a reciprocal translocation, approximately $80 \%$ of the resulting embryos will contain an incorrect amount of genetic material.

Robertsonian translocations occur when two chromosomes join together to form one large chromosome, giving an overall chromosome count of 45 instead of 46 . Inversions are chromosome rearrangements that involve only one chromosome. In an inversion, a segment of a chromosome is flipped and reinserted upside down. People with an inversion may create embryos with missing or duplicated segments of chromosomes.

\section{IVF-ICSI and PGT for monogenic disorders}

PGT for monogenic disorders (PGT-M) is an increasingly popular technology that allows couples affected by or known to be at risk for a genetic disease to avoid passing on the condition to the next generation. It is used in conjunction with IVF, after which the embryos are biopsied to test for the specific gene mutation before implantation and pregnancy.

Common indications for PGT-M include cystic fibrosis, spinal muscular atrophy, hereditary hemoglobinopathies, and Huntington disease; however, its indications are rapidly expanding in the post-human genome sequencing era. The transmission of genetic urological disorders, such as Alport syndrome, autosomal dominant polycystic kidney disease, and Von Hippel-Lindau syndrome, could also be prevented by IVF-ICSI and PGT-M $[76,77]$. Many single-gene mutations linked with spermatogenesis (e.g., mutations in X-linked, Y-linked, and autosomal genes) could be detected by PGT-M, enabling the prevention of disease complications (Table 3).

\section{Conclusion}

Previously, karyotype analyses and Y-chromosome microdeletion tests were used as effective techniques for detecting the etiology of azoospermia or severe oligozoospermia. However, in recent years, the indications for these tests have been revised to include abnormalities in X-linked and autosomal genes related to genetic infertility, as well as sex chromosome abnormalities and Y-chromosome ab- 
normalities. Male infertility related to impaired spermatogenesis is associated with multiple factors and exhibits genetic heterogeneity, and it is necessary to identify additional candidate genes that may be related to male infertility.

With rapid advances in genetic diagnostic tools, such as next-generation sequencing, single genes related to azoospermia, cryptozoospermia, asthenozoospermia, and specific morphological abnormalities have been identified, resulting in a decrease in "idiopathic" male infertility. Personalized hormonal treatment, genetic counseling, and IVF-ICSI with PGT could prevent the transmission of genetic disorders and enable the implantation of normal embryos, thereby improving pregnancy rates in infertile men with genetic diseases. Additionally, cost-benefit analyses of genetic studies should be investigated in future research.

\section{Conflict of interest}

No potential conflict of interest relevant to this article was reported.

\section{ORCID}

Seung Ryeol Lee
Tae Ho Lee
Seung-Hun Song
Dong Suk Kim
Kyung Hwa Choi
Jae Ho Lee
Dae Keun Kim

https://orcid.org/0000-0002-9959-3488 https://orcid.org/0000-0002-6797-1042 https://orcid.org/0000-0003-4649-9129 https://orcid.org/0000-0001-7350-0303 https://orcid.org/0000-0001-9421-9596 https://orcid.org/0000-0001-7750-6032 https://orcid.org/0000-0003-3237-6304

\section{Author contributions}

Conceptualization: SHS. Formal analysis: DSK, SRL. Data curation: KHC. Project administration: JHL. Investigation: THL, DKK. Writingoriginal draft: DKK, THL. Writing-review \& editing: SRL, DKK.

\section{References}

1. Agarwal A, Majzoub A, Baskaran S, Panner Selvam MK, Cho CL, Henkel R, et al. Sperm DNA fragmentation: a new guideline for clinicians. World J Mens Health 2020;38:412-71.

2. Del Giudice F, Kasman AM, Ferro M, Sciarra A, De Berardinis E, Belladelli $\mathrm{F}$, et al. Clinical correlation among male infertility and overall male health: a systematic review of the literature. Investig Clin Urol 2020;61:355-71.

3. Song SH, Chiba K, Ramasamy R, Lamb DJ. Recent advances in the genetics of testicular failure. Asian J Androl 2016;18:350-5.
4. Asero P, Calogero AE, Condorelli RA, Mongioi L, Vicari E, Lanzafame $F$, et al. Relevance of genetic investigation in male infertility. J Endocrinol Invest 2014;37:415-27.

5. Song SH, Park SH, Shin E, Jung JH, Shim SH, Kim DS. Male infertility associated with a supernumerary marker chromosome. World J Mens Health 2017;35:205-8.

6. Tuttelmann F, Ruckert C, Ropke A. Disorders of spermatogenesis: perspectives for novel genetic diagnostics after 20 years of unchanged routine. Med Genet 2018;30:12-20.

7. Thirumavalavan N, Gabrielsen JS, Lamb DJ. Where are we going with gene screening for male infertility? Fertil Steril 2019;111: $842-50$.

8. Lee I, Alur-Gupta S, Gallop R, Dokras A. Utilization of preimplantation genetic testing for monogenic disorders. Fertil Steril 2020; 114:854-60.

9. Lee HS, Kim MJ, Ko DS, Jeon EJ, Kim JY, Kang IS. Preimplantation genetic diagnosis for Charcot-Marie-Tooth disease. Clin Exp Reprod Med 2013;40:163-8.

10. Schlegel PN, Sigman M, Collura B, De Jonge CJ, Eisenberg ML, Lamb DJ, et al. Diagnosis and treatment of infertility in men: AUA/ ASRM guideline part I. Fertil Steril 2021;115:54-61.

11. Jungwirth A, Giwercman A, Tournaye H, Diemer T, Kopa Z, Dohle $G$, et al. European Association of Urology guidelines on male infertility: the 2012 update. Eur Urol 2012;62:324-32.

12. Dul EC, van Ravenswaaij-Arts CM, Groen H, van Echten-Arends J, Land JA. Who should be screened for chromosomal abnormalities before ICSI treatment? Hum Reprod 2010;25:2673-7.

13. Cimadomo D, Craciunas L, Vermeulen N, Vomstein K, Toth B. Definition, diagnostic and therapeutic options in recurrent implantation failure: an international survey of clinicians and embryologists. Hum Reprod 2021;36:305-17.

14. Kohn TP, Kohn JR, Owen RC, Coward RM. The prevalence of Y-chromosome microdeletions in oligozoospermic men: a systematic review and meta-analysis of European and North American studies. Eur Urol 2019;76:626-36.

15. Fruhmesser A, Kotzot D. Chromosomal variants in Klinefelter syndrome. Sex Dev 2011;5:109-23.

16. Belling K, Russo F, Jensen AB, Dalgaard MD, Westergaard D, Rajpert-De Meyts $\mathrm{E}$, et al. Klinefelter syndrome comorbidities linked to increased $X$ chromosome gene dosage and altered protein interactome activity. Hum Mol Genet 2017;26:1219-29.

17. Rohayem J, Fricke R, Czeloth K, Mallidis C, Wistuba J, Krallmann C, et al. Age and markers of Leydig cell function, but not of Sertoli cell function predict the success of sperm retrieval in adolescents and adults with Klinefelter's syndrome. Andrology 2015;3:86875.

18. Wong EC, Ferguson KA, Chow V, Ma S. Sperm aneuploidy and 
meiotic sex chromosome configurations in an infertile XYY male. Hum Reprod 2008;23:374-8.

19. Speed RM, Faed MJ, Batstone PJ, Baxby K, Barnetson W. Persistence of two $Y$ chromosomes through meiotic prophase and metaphase I in an XYY man. Hum Genet 1991;87:416-20.

20. de la Chapelle A. Analytic review: nature and origin of males with XX sex chromosomes. Am J Hum Genet 1972;24:71-105.

21. Vorona E, Zitzmann M, Gromoll J, Schuring AN, Nieschlag E. Clinical, endocrinological, and epigenetic features of the $46, X X$ male syndrome, compared with 47,XXY Klinefelter patients. J Clin Endocrinol Metab 2007;92:3458-65.

22. Wu QY, Li N, Li WW, Li TF, Zhang C, Cui YX, et al. Clinical, molecular and cytogenetic analysis of $46, \mathrm{XX}$ testicular disorder of sex development with SRY-positive. BMC Urol 2014;14:70.

23. Frydman N, Romana S, Le Lorc'h M, Vekemans M, Frydman R, Tachdjian G. Assisting reproduction of infertile men carrying a Robertsonian translocation. Hum Reprod 2001;16:2274-7.

24. Antonelli A, Gandini L, Petrinelli P, Marcucci L, Elli R, Lombardo F, et al. Chromosomal alterations and male infertility. J Endocrinol Invest 2000;23:677-83.

25. Martin RH. Cytogenetic determinants of male fertility. Hum Reprod Update 2008;14:379-90.

26. Dong Y, Du RC, Jiang YT, Wu J, Li LL, Liu RZ. Impact of chromosomal translocations on male infertility, semen quality, testicular volume and reproductive hormone levels. J Int Med Res 2012;40: 2274-83.

27. Chang L, Chen SU, Tsai YY, Hung CC, Fang MY, Su YN, et al. An update of preimplantation genetic diagnosis in gene diseases, chromosomal translocation, and aneuploidy screening. Clin Exp Reprod Med 2011;38:126-34.

28. Guttenbach M, Engel W, Schmid M. Analysis of structural and numerical chromosome abnormalities in sperm of normal men and carriers of constitutional chromosome aberrations: a review. Hum Genet 1997;100:1-21.

29. Anton E, Blanco J, Egozcue J, Vidal F. Sperm studies in heterozygote inversion carriers: a review. Cytogenet Genome Res 2005; 111:297-304.

30. Anton E, Vidal F, Egozcue J, Blanco J. Genetic reproductive risk in inversion carriers. Fertil Steril 2006;85:661-6.

31. Dagdeviren Cakir A, Bas F, Akin O, Siklar Z, Ozcabi B, Berberoglu M, et al. Clinical characteristics and growth hormone treatment in patients with Prader-Willi syndrome. J Clin Res Pediatr Endocrinol 2021;13:308-19.

32. Fisher K, Keng J, Ziegler J. Nutrition assessment and intervention in a pediatric patient with angelman syndrome: a case presentation highlighting clinical challenges and evidence-based solutions. Lifestyle Genom 2020;13:43-52.
33. Ramirez-Velazco A, Aguayo-Orozco TA, Figuera L, Rivera H, Jave-Suarez L, Aguilar-Lemarroy A, et al. Williams-Beuren syndrome in Mexican patients confirmed by FISH and assessed by aCGH. J Genet 2019;98:34.

34. Simoni M, Gromoll J, Dworniczak B, Rolf C, Abshagen K, Kamischke $A$, et al. Screening for deletions of the $Y$ chromosome involving the DAZ (Deleted in AZoospermia) gene in azoospermia and severe oligozoospermia. Fertil Steril 1997;67:542-7.

35. Krausz C, Casamonti E. Spermatogenic failure and the Y chromosome. Hum Genet 2017;136:637-55.

36. Kamp C, Huellen K, Fernandes S, Sousa M, Schlegel PN, Mielnik A, et al. High deletion frequency of the complete AZFa sequence in men with Sertoli-cell-only syndrome. Mol Hum Reprod 2001;7: 987-94.

37. Vogt PH. Azoospermia factor (AZF) in Yq11: towards a molecular understanding of its function for human male fertility and spermatogenesis. Reprod Biomed Online 2005;10:81-93.

38. Skaletsky H, Kuroda-Kawaguchi T, Minx PJ, Cordum HS, Hillier L, Brown $L G$, et al. The male-specific region of the human $Y$ chromosome is a mosaic of discrete sequence classes. Nature 2003; 423:825-37.

39. Elliott DJ. The role of potential splicing factors including RBMY, RBMX, hnRNPG-T and STAR proteins in spermatogenesis. Int J Androl 2004;27:328-34.

40. Colaco S, Modi D. Genetics of the human Y chromosome and its association with male infertility. Reprod Biol Endocrinol 2018; 16:14.

41. Kleiman SE, Yogev L, Lehavi O, Hauser R, Botchan A, Paz G, et al. The likelihood of finding mature sperm cells in men with AZFb or AZFb-c deletions: six new cases and a review of the literature (1994-2010). Fertil Steril 2011;95:2005-12.

42. Kuroda S, Usui K, Sanjo H, Takeshima T, Kawahara T, Uemura H, et al. Genetic disorders and male infertility. Reprod Med Biol 2020; 19:314-22

43. Oates RD, Silber S, Brown LG, Page DC. Clinical characterization of 42 oligospermic or azoospermic men with microdeletion of the AZFc region of the $Y$ chromosome, and of 18 children conceived via ICSI. Hum Reprod 2002;17:2813-24.

44. Saxena R, de Vries JW, Repping S, Alagappan RK, Skaletsky H, Brown $L G$, et al. Four DAZ genes in two clusters found in the AZFC region of the human Y chromosome. Genomics 2000;67:256-67.

45. Gatta V, Stuppia L, Calabrese G, Morizio E, Guanciali-Franchi P, Palka G. A new case of Yq microdeletion transmitted from a normal father to two infertile sons. J Med Genet 2002;39:E27.

46. Krausz C, Forti G. Sperm cryopreservation in male infertility due to genetic disorders. Cell Tissue Bank 2006;7:105-12.

47. Hopps CV, Mielnik A, Goldstein M, Palermo GD, Rosenwaks Z, 
Schlegel PN. Detection of sperm in men with $\mathrm{Y}$ chromosome microdeletions of the AZFa, AZFb and AZFc regions. Hum Reprod 2003;18:1660-5.

48. Yamauchi Y, Riel JM, Ruthig V, Ward MA. Mouse Y-encoded transcription factor Zfy 2 is essential for sperm formation and function in assisted fertilization. PLoS Genet 2015;11:e1005476.

49. Vernet N, Mahadevaiah SK, Yamauchi Y, Decarpentrie F, Mitchell MJ, Ward MA, et al. Mouse Y-linked Zfy1 and Zfy2 are expressed during the male-specific interphase between meiosis I and meiosis II and promote the 2nd meiotic division. PLoS Genet 2014;10: e1004444.

50. Li Y, Zhang DJ, Qiu Y, Kido T, Lau YC. The Y-located proto-oncogene TSPY exacerbates and its X-homologue TSPX inhibits transactivation functions of androgen receptor and its constitutively active variants. Hum Mol Genet 2017;26:901-12.

51. Yatsenko AN, Georgiadis AP, Ropke A, Berman AJ, Jaffe T, Olszewska M, et al. X-linked TEX11 mutations, meiotic arrest, and azoospermia in infertile men. N Engl J Med 2015;372:2097-107.

52. Boroujeni PB, Sabbaghian M, Totonchi M, Sodeifi N, Sarkardeh H, Samadian A, et al. Expression analysis of genes encoding TEX11, TEX12, TEX14 and TEX15 in testis tissues of men with non-obstructive azoospermia. JBRA Assist Reprod 2018;22:185-92.

53. Yang F, Eckardt S, Leu NA, McLaughlin KJ, Wang PJ. Mouse TEX15 is essential for DNA double-strand break repair and chromosomal synapsis during male meiosis. J Cell Biol 2008;180:673-9.

54. Kotov AA, Olenkina OM, Godneeva BK, Adashev VE, Olenina LV. Progress in understanding the molecular functions of DDX3Y (DBY) in male germ cell development and maintenance. Biosci Trends 2017;11:46-53.

55. Foresta C, Ferlin A, Moro E. Deletion and expression analysis of AZFa genes on the human $Y$ chromosome revealed a major role for DBY in male infertility. Hum Mol Genet 2000;9:1161-9.

56. Bashamboo A, Ferraz-de-Souza B, Lourenco D, Lin L, Sebire NJ, Montjean $D$, et al. Human male infertility associated with mutations in NR5A1 encoding steroidogenic factor 1. Am J Hum Genet 2010;87:505-12.

57. Mou L, Wang Y, Li H, Huang Y, Jiang T, Huang W, et al. A dominant-negative mutation of HSF2 associated with idiopathic azoospermia. Hum Genet 2013;132:159-65.

58. Vinci G, Chantot-Bastaraud S, El Houate B, Lortat-Jacob S, Brauner R, McElreavey K. Association of deletion 9p, 46,XY gonadal dysgenesis and autistic spectrum disorder. Mol Hum Reprod 2007; 13:685-9.

59. Lopes AM, Aston KI, Thompson E, Carvalho F, Goncalves J, Huang $\mathrm{N}$, et al. Human spermatogenic failure purges deleterious mutation load from the autosomes and both sex chromosomes, including the gene DMRT1. PLoS Genet 2013;9:e1003349.
60. Amiri-Yekta A, Coutton C, Kherraf ZE, Karaouzene T, Le Tanno P, Sanati MH, et al. Whole-exome sequencing of familial cases of multiple morphological abnormalities of the sperm flagella (MMAF) reveals new DNAH1 mutations. Hum Reprod 2016;31: 2872-80.

61. Knowles MR, Zariwala M, Leigh M. Primary ciliary dyskinesia. Clin Chest Med 2016;37:449-61.

62. Coutton C, Escoffier J, Martinez G, Arnoult C, Ray PF. Teratozoospermia: spotlight on the main genetic actors in the human. Hum Reprod Update 2015;21:455-85.

63. Collodel G, Moretti E. Sperm morphology and aneuploidies: defects of supposed genetic origin. Andrologia 2006;38:208-15.

64. Ben Khelifa M, Coutton C, Zouari R, Karaouzene T, Rendu J, Bidart $\mathrm{M}$, et al. Mutations in DNAH1, which encodes an inner arm heavy chain dynein, lead to male infertility from multiple morphological abnormalities of the sperm flagella. Am J Hum Genet 2014;94: 95-104.

65. Okutman O, Rhouma MB, Benkhalifa M, Muller J, Viville S. Genetic evaluation of patients with non-syndromic male infertility. J Assist Reprod Genet 2018;35:1939-51.

66. Harbuz R, Zouari R, Pierre V, Ben Khelifa M, Kharouf M, Coutton C, et al. A recurrent deletion of DPY19L2 causes infertility in man by blocking sperm head elongation and acrosome formation. Am J Hum Genet 2011;88:351-61.

67. Hussein A, Ozgok Y, Ross L, Rao P, Niederberger C. Optimization of spermatogenesis-regulating hormones in patients with non-obstructive azoospermia and its impact on sperm retrieval: a multicentre study. BJU Int 2013;111(3 Pt B):E110-4.

68. Ring JD, Lwin AA, Kohler TS. Current medical management of endocrine-related male infertility. Asian J Androl 2016;18:357-63.

69. Schlegel PN. Aromatase inhibitors for male infertility. Fertil Steril 2012;98:1359-62.

70. Raven G, de Jong FH, Kaufman JM, de Ronde W. In men, peripheral estradiol levels directly reflect the action of estrogens at the hypothalamo-pituitary level to inhibit gonadotropin secretion. $J$ Clin Endocrinol Metab 2006;91:3324-8.

71. Del Giudice F, Busetto GM, De Berardinis E, Sperduti I, Ferro M, Maggi $M$, et al. A systematic review and meta-analysis of clinical trials implementing aromatase inhibitors to treat male infertility. Asian J Androl 2020;22:360-7.

72. Shiraishi K, Ohmi C, Shimabukuro T, Matsuyama H. Human chorionic gonadotrophin treatment prior to microdissection testicular sperm extraction in non-obstructive azoospermia. Hum Reprod 2012;27:331-9.

73. Ramasamy R, Ricci JA, Palermo GD, Gosden LV, Rosenwaks Z, Schlegel PN. Successful fertility treatment for Klinefelter's syndrome. J Urol 2009;182:1108-13. 
74. Handyside AH, Kontogianni EH, Hardy K, Winston RM. Pregnancies from biopsied human preimplantation embryos sexed by Y-specific DNA amplification. Nature 1990;344:768-70.

75. Zegers-Hochschild F, Adamson GD, Dyer S, Racowsky C, de Mouzon J, Sokol R, et al. The International Glossary on Infertility and Fertility Care, 2017. Fertil Steril 2017;108:393-406.

76. Snoek R, Stokman MF, Lichtenbelt KD, van Tilborg TC, Simcox CE,
Paulussen $\mathrm{AD}$, et al. Preimplantation genetic testing for monogenic kidney disease. Clin J Am Soc Nephrol 2020;15:1279-86.

77. Obradors A, Fernandez E, Rius M, Oliver-Bonet M, Martinez-Fresno M, Benet J, et al. Outcome of twin babies free of Von Hippel-Lindau disease after a double-factor preimplantation genetic diagnosis: monogenetic mutation analysis and comprehensive aneuploidy screening. Fertil Steril 2009;91:933. 